\title{
Negative energy balance and leptin regulate neuromedin- $U$ expression in the rat pars tuberalis
}

\author{
Ruben Nogueiras, Sulay Tovar, Sharon E Mitchell ${ }^{1}$, Perry Barrett ${ }^{1}$, D Vernon Rayner ${ }^{1}$, Carlos Dieguez \\ and Lynda $\mathbf{M}$ Williams ${ }^{1}$
}

Department of Physiology, University of Santiago de Compostela, 15705 Santiago de Compostela, Spain

${ }^{1}$ Obesity and Metabolic Health Division, Rowett Research Institute, Aberdeen AB21 9SB, UK

(Requests for offprints should be addressed to L M Williams; Email: I.williams@rri.sari.ac.uk)

\begin{abstract}
Central neuromedin $\mathrm{U}$ (NMU) functions in energy balance, the hypothalamic-pituitary-adrenal axis, LH release and circadian rhythmicity. In rats, high levels of NMU occur in the hypothalamic suprachiasmatic nuclei and the pars tuberalis of the pituitary. NMU expression in the pars tuberalis appears to be downregulated in the Zucker fatty $(f a / f a)$ rat, lacking functional leptin receptors. In contrast, in the dorsomedial $(\mathrm{DMH})$ nuclei of the mouse, NMU expression is higher in the $o b / o b$ mouse, lacking leptin, and is upregulated by fasting. However, leptin appears not to change NMU gene expression in either the mouse DMH or the rat pars tuberalis. Thus, the present study aims to better identify factors influencing central NMU expression in the rat pars tuberalis. SpragueDawley rats were fasted and/or challenged with intracerebroventricular leptin or ghrelin and gene expression was
\end{abstract}

measured using real-time reverse transcriptase-PCR and quantitative in situ hybridisation with riboprobes specific for NMU and NMU receptor (NMU-R2). NMU expression in the rat pars tuberalis was elevated by fasting. Ghrelin administration had no effect on the level of NMU expression, but leptin was found to diminish the expression in a concentration- and time-dependent manner. NMU-R2 expression was unchanged in any of the groups measured. These results suggest that NMU expression in rat pars tuberalis is upregulated in states of negative energy balance, and this may be mediated indirectly by changes in leptin levels. These results demonstrate a link between energy balance and NMU expression in the pars tuberalis of the pituitary.

Journal of Endocrinology (2006) 190, 545-553

\section{Introduction}

Neuromedin U (NMU) was first isolated from porcine spinal cord and named for its potent contractile activity on the uterus. It is a highly conserved molecule existing in two molecular forms: an octapeptide (NMU-8) constituting the core active $\mathrm{C}$ terminus and complete 25 amino acid peptide, NMU-25 (Minamino et al. 1985). In the mouse central nervous system, NMU is expressed in the suprachiasmatic $(\mathrm{SCN})$, dorsomedial $(\mathrm{DMH})$, ventromedial $(\mathrm{VMH})$ and arcuate nuclei of the hypothalamus (Graham et al. 2003). These nuclei are important in controlling circadian rhythms, appetite and energy balance (Takahashi \& Zatz 1982, Williams et al. 2001). In contrast, NMU expression in the rat is limited to the SCN, relatively few diffuse cells in the arcuate nuclei and $\mathrm{DMH}$ in the hypothalamus and the nuclei of the solitary tract (NTS) and the inferior olive in the brainstem (Ivanov et al. 2002, Graham et al. 2003). However, relatively high levels of NMU are found in the pars tuberalis of the pituitary, which adheres closely to the ventral edge of the hypothalamic median eminence (Ivanov et al. 2002, Graham et al. 2003). Specific central receptors for NMU
(NMU-R2) are highly localised to the hypothalamic paraventricular nucleus (PVN), the ependymal lining of the hypothalamic third ventricle and the hippocampus (Howard et al. 2000, Guan et al. 2001, Graham et al. 2003). Central administration of NMU stimulates the hypothalamo-pituitary-adrenal axis (Hanada et al. 2001, Wren et al. 2002, Thompson et al. 2004), suppresses food intake and body weight gain, increases gross locomotor activity, body temperature and heat production (Howard et al. 2000, Nakazato et al. 2000). It is also involved in the regulation of circadian rhythmicity (Nakahara et al. 2004) and luteinizing hormone secretion (Quan et al. 2003). The NMU knockout mouse is hyperphagic and obese (Hanada et al. 2004), while the transgenic mouse, overexpressing NMU, is lean and hypophagic (Kowalski et al. 2005) providing strong support for the role of NMU in energy balance.

The circulating hormones, leptin and ghrelin act in opposition to one another to alter the hypothalamic gene expression of peptides involved in energy balance to maintain body weight homeostasis (Zigman \& Elmquist 2003). Leptin is secreted by, and in proportion to, the white adipose tissue and signals the status of energy stores to the hypothalamus, 
inhibits feeding and increases energy expenditure (Elias et al. 1999). Leptin levels are lowered by fasting and food restriction (Ahren et al. 1997, Keim et al. 1998). Circulating levels of ghrelin, secreted by the stomach, rise rapidly in response to fasting and drop rapidly after feeding, and act as a short-term signal of nutrient depletion (Lee et al. 2002) stimulating feeding and decreasing energy expenditure via ghrelin receptors (GHS-R) in the arcuate nuclei and VMH (Kamegai et al. 2001, Cowley et al. 2003). Ghrelin levels are raised during fasting and decreased in obesity (Tschop et al. 2001, Kim et al. 2003).

Influence of the peripheral hormones, leptin and ghrelin, on central NMU expression is at present unclear. Leptin treatment of NMU knockout mice reduces their body weight to a similar extent as wild-type mice (Hanada et al. 2004), indicating that the NMU system is not necessary for the central effects of leptin on appetite and body weight, despite this, NMU has been shown to partially mediate the effects of leptin on food intake in the rat (Jethwa et al. 2005). The level of NMU expression in the DMH of the genetically obese, leptin-deficient, $o b / o b$ mouse, is higher than in wild-type littermates and NMU gene expression in this region is also elevated in response to fasting (Graham et al. 2003), a state in which leptin levels are lowered. These findings suggest a potential link between circulating leptin levels and regulation of central NMU gene expression. However, peripheral administration of leptin failed to change NMU gene expression in these mice (Graham et al. 2003). In contrast to the findings in DMH, NMU gene expression was found to be lower in the SCN of ob/ob mice compared to lean littermates (Howard et al. 2000). The level of NMU gene expression in the SCN of normal mice has also been found to show a strong circadian rhythmicity (Graham et al. 2005). In the Zucker fatty rat $(f a / f a)$, which lacks a functional leptin receptor, the level of NMU gene expression in the pars tuberalis and pars distalis of the pituitary and the NTS is lower than in the Zucker lean animal $(f a /+)$, and fasting was reported to diminish the number of cells expressing NMU in the nuclei of the solitary tract and NMU gene expression in the pars distalis (Ivanov et al. 2002) and VMH (Howard et al. 2000), implicating leptin in the control of NMU expression in the brainstem hypothalamus and pituitary of the rat. However, in another study, leptin administration has been reported to have no effect on the level of gene expression in the pars tuberalis of the rat, which was erroneously identified as the arcuate nuclei (Hanada et al. 2004). This indicates that the effect of fasting on NMU gene expression may be mediated via factors other than leptin.

Circulating levels of ghrelin are known to rise during fasting, in contrast to the drop in circulating leptin levels, and could potentially influence NMU gene expression. The effects of ghrelin on NMU expression have not been reported. Thus, in order to clarify the effects of fasting and the roles of both leptin and ghrelin in the regulation of NMU gene expression in the rat mediobasal hypothalamus and pars tuberalis of the pituitary gland, we have measured NMU gene expression in Sprague-Dawley rats in response to fasting and to i.c.v.-administered leptin and ghrelin, first using real-time reverse transcriptase (RT)-PCR and secondly using the more sensitive and tissue-precise technique of quantitative in situ hybridisation. Gene expression of NMU-R2 in the PVN was also measured.

\section{Material and Methods}

\section{Experimental animals}

Male Sprague-Dawley rats between 8 and 10 weeks of age were obtained from Harlan Ibérica (Barcelona, Spain) and housed at the University of Santiago de Compostela, where all experimental procedures were performed. The animals were maintained in air-conditioned rooms $\left(22-24^{\circ} \mathrm{C}\right)$ under a controlled $14 \mathrm{~h}$ light: $14 \mathrm{~h}$ darkness cycle and fed ad libitum with standard rat chow and water, unless otherwise indicated. Animals were killed by decapitation in a room separate from other experimental animals. Brains were removed rapidly, frozen and stored at $-80^{\circ} \mathrm{C}$ until cryosectioned and processed for in situ hybridisation. Serial sections from these animals were also used as part of a related study looking at the interactions between leptin and ghrelin on GHS-R expression (Nogueiras et al. 2004), thus supporting the ethos of reduction of animal numbers in experimentation. All animal experimental procedures were conducted according to the regulations of Santiago de Compostela Medical School Animal Care Research Committee.

\section{Implantation of i.c.v. cannulas}

Animals were anaesthetised by an i.p. injection of a mixture of ketamine/xylazine (ketamine $100 \mathrm{mg} / \mathrm{kg}$ BW + xylazine $15 \mathrm{mg} / \mathrm{kg} \mathrm{BW}$ ). Chronic i.c.v. cannulas were implanted stereotaxically using the following coordinates: $1.3 \mathrm{~mm}$ posterior to bregma, $1.9 \mathrm{~mm}$ lateral to the midsagittal suture and to a depth of $3.5 \mathrm{~mm}$ as described previously (Seoane et al. 2003). The location of the cannula in the lateral ventricle was confirmed by methylene blue staining. Animals were caged individually and allowed to recover for a week prior to experiment. During the post-operative recovery period, the rats were handled regularly under non-stressful conditions.

\section{Short-term ghrelin and leptin challenge}

At the start of the experiment, one group of rats continued to be fed ad libitum and the other group was deprived of food for $48 \mathrm{~h}$. Rats then received either a single i.c.v. injection of ghrelin (Bachem, Bubendorf, Switzerland; $5 \mu \mathrm{g} /$ rat dissolved in $5 \mu$ distilled water saturated with argon; $n=6$ ) or vehicle (control rats; $n=6$ ). Rats were killed $2 \mathrm{~h}$ after injection. In a separate experiment, rats were fed ad libitum and received a single i.c.v. injection of either ghrelin or vehicle and were killed either $1(n=6)$ or $2 \mathrm{~h}(n=6)$ after the injection. 
All treatments started at $0900 \mathrm{~h}$ and were carried out in the light-phase. In a separate experiment, animals were either fed ad libitum or fasted for $48 \mathrm{~h}$ as described above. A single i.c.v. injection of $5 \mu \mathrm{l}$ containing $10 \mu \mathrm{g} / \mathrm{rat}$ of recombinant human leptin (Sigma) $(n=6)$ or carrier $(n=6)$ was given to the animals and were killed $2 \mathrm{~h}$ later. The doses of both ghrelin and leptin and the time of sampling after injection were decided on the basis of previous experiments, where measurable changes in gene expression have been documented at these doses and times after administration (Lopez et al. 2000, Seoane et al. 2003).

\section{Long-term leptin challenge}

Brain-infusion cannulas were stereotaxically placed into the lateral ventricle as described above. A catheter tube was connected from the brain-infusion cannula to the osmotic minipump flow moderator (model 2ML2; Alza Corp., Palo Alto, CA, USA). An s.c. pocket on the dorsal surface was created using blunt dissection and the osmotic minipump was inserted. The incision was closed with sutures, and the rats were kept warm until completely recovered. Rats were then infused with either recombinant human leptin $(15 \mu \mathrm{g} /$ day $)$ or carrier $(n=12)$ for $24(n=6), 48 \mathrm{~h}(n=6)$ and 7 days $(n=12)$ into the lateral ventricle. For the last $48 \mathrm{~h}$ of the 7 -day infusion period, rats were fed either ad libitum or fasted $(n=6$ leptin and $n=6$ carrier in both groups). During this time, rats were kept in grid-bottomed cages to facilitate food intake measurements and weighed daily. In a separate experiment, rats were infused with leptin $(1 \mu \mathrm{g} /$ day; $n=6)$ or $(5 \mu \mathrm{g} /$ day; $n=6$ ) for 7 days as described above.

\section{RNA extraction and real-time RT-PCR}

Total RNA was extracted by Trizol reagent (Invitrogen). Rat hypothalamic expression of the mRNA-encoding NMU was assessed by real-time RT-PCR. Total RNA $(2 \mu \mathrm{g})$ was reverse transcribed using random primer and Superscript III reverse transcriptase (Invitrogen). Real-time RT-PCR analyses were performed in the ABI 7700 sequence detection system (Perkin-Elmer Applied Biosystems, Foster City, CA, USA). Reactions were performed in duplicate. The synthesised cDNAs were further amplified by PCR using SYBR Green I as fluorescent dye and $1 \times \mathrm{PCR}$ Master Mix (Applied Biosystems) containing $300 \mathrm{nmol} / 1$ of forward and reverse primers, in a final volume of $25 \mu \mathrm{l}$. All reactions were carried out using the following cycling parameters: $50{ }^{\circ} \mathrm{C}$ for $2 \mathrm{~min}$ and $95^{\circ} \mathrm{C}$ for $10 \mathrm{~min}$, followed by 40 cycles of $95^{\circ} \mathrm{C}$ for $15 \mathrm{~s}$ and $60{ }^{\circ} \mathrm{C}$ for $1 \mathrm{~min}$. Product purity was confirmed by dissociation curves and random agarose gel electrophoresis. No template controls were included in all the assays, yielding no consistent amplification. Standard curves were constructed for each specific target and the internal control by plotting values of $\mathrm{CT}$ (the cycle at which the fluorescence signal exceeds background) versus log cDNA input (in nanograms). Accordingly, CT values from each experimental sample were then used to calculate the amount of each gene and ciclophiline A mRNAs relative to the standard. For each sample, results in terms of gene expression levels were normalised to those of the internal control, ciclophiline A.

The oligonucleotide-specific primers for rat NMU and ciclophiline A are as follows: NMU forward $5^{\prime}$-TGC GTC CTT TCT GTC TGT TG-3'; reverse 5'-TCA TGC AGT TGA GGA ACG AG-3'; ciclophiline A forward $5^{\prime}-\mathrm{AGC}$ ACT GGG GAG AAA GGA TT-3'; reverse $5^{\prime}$-CAT GCC TTC TTT CAC CTT CC-3'.

\section{In situ hybridisation}

The mRNA levels for rat NMU, Ob-Rb and NMU-R2 were quantified using specific probes derived as previously described (Graham et al. 2003) using quantitative in situ hybridisation (Mitchell et al. 2002). Briefly, $20 \mu \mathrm{m}$ thick, coronal hypothalamic section was fixed in $4 \%(\mathrm{w} / \mathrm{v})$ paraformaldehyde in $0 \cdot 1 \mathrm{~mol} / 1 \mathrm{PBS}$ for $20 \mathrm{~min}$ at room temperature, washed in PBS, incubated in $0.1 \mathrm{mmol} / 1$ triethanolamine for $2 \mathrm{~min}$ and acetylated in $0 \cdot 1 \mathrm{mmol} / 1$ triethanolamine and $0 \cdot 25 \%(\mathrm{v} / \mathrm{v})$ acetic anhydride for $10 \mathrm{~min}$. Sections were dehydrated through a graded series of ethanol and dried under vacuum before hybridisation with riboprobes at $10^{6}$ c.p.m. $/ \mathrm{ml}$ for $18 \mathrm{~h}$ at $58{ }^{\circ} \mathrm{C}$. After hybridisation, sections were desalted through a series of washes in SSC to a final stringency of $0 \cdot 1 \times$ SSC at $60{ }^{\circ} \mathrm{C}$ for $30 \mathrm{~min}$, treated with RNase A and dehydrated in ethanol. Air-dried slides were apposed to Biomax MR (Sigma) together with autoradiographic $\left({ }^{14} \mathrm{C}\right)$ microscale standards (Amersham) for 1 week at room temperature, for autoradiography. Slides were then dipped in Hypercoat LM-1 Nuclear Emulsion (Amersham) and exposed for approximately 1 month for light microscopy. Images were captured on a Leica DMR microscope equipped with Hamamatsu C5810-10 3CCD colour camera using Image Pro Plus software (Media Cybernetics, Berks, UK).

\section{Quantification of in situ hybridisation}

Autoradiographs of sections and $\left({ }^{14} \mathrm{C}\right)$ microscale standards were scanned on Umax Power Look II (UMAX Data Systems, Fremont, CA, USA). Integrated optical densities of pars tuberalis and PVN were measured using the Image ProPlus system (Media Cybernetics) and converted to $\mathrm{nCi} / \mathrm{g}$ using a standard curve generated from the $\left({ }^{14} \mathrm{C}\right)$ microscales. Values were then converted to percentages of control values $(100 \%)$ for each separate in situ hybridisation experiment in order to combine the data.

\section{Statistical analysis}

Data were represented as means \pm s.E.M. and analysed (Fig. 2-5) by two-way ANOVA followed by Student-Newman-Keuls method. For experiments where the effect of leptin vs saline infusion were compared on body weight and food intake and where the time and dose dependency of leptin treatment were 
measured (Fig. 6) data were analysed by one-way ANOVA. A value of $P<0 \cdot 05$ was considered statistically significant.

\section{Results}

Localisation of $N M U$ and $O b-R b$ gene expression

NMU gene expression is clearly localised to the pars tuberalis of the pituitary (Fig. 1A). There is no apparent overlap

(A)

$$
\text { NMU }
$$

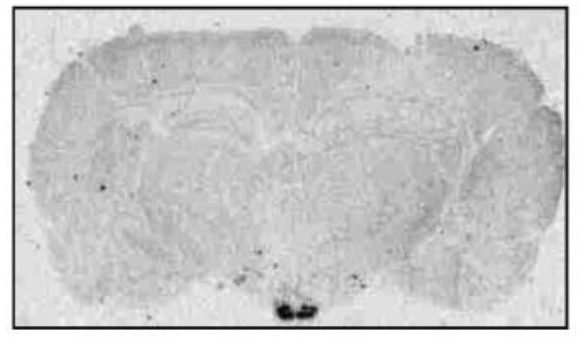

(D)

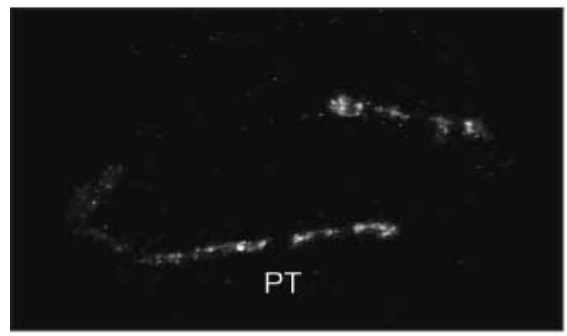

between NMU gene expression and $\mathrm{Ob}-\mathrm{Rb}$ gene expression, which is localised to several nuclei in the mediobasal hypothalamus with no apparent expression over the pars tuberalis (Fig. 1B and C). Dark-field microscopy of NMU gene expression on emulsion-coated slides shows a thin layer of silver grains (Fig. 1D) corresponding to the pars tuberalis at the outer edge of the median eminence (Fig. 1E and F). A number of relatively diffuse and sparsely labelled NMUexpressing neurons were seen in the arcuate and $\mathrm{VMH}$ as

(B) $\quad \mathrm{Ob}-\mathrm{Rb}$

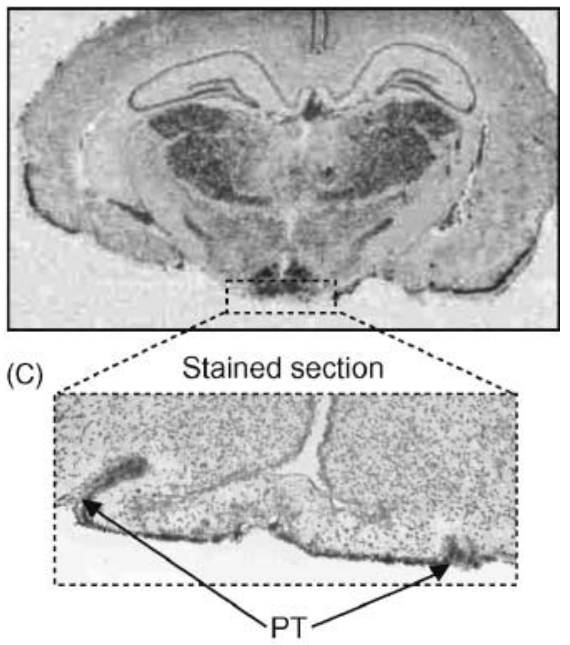

(E)

NMU bright field

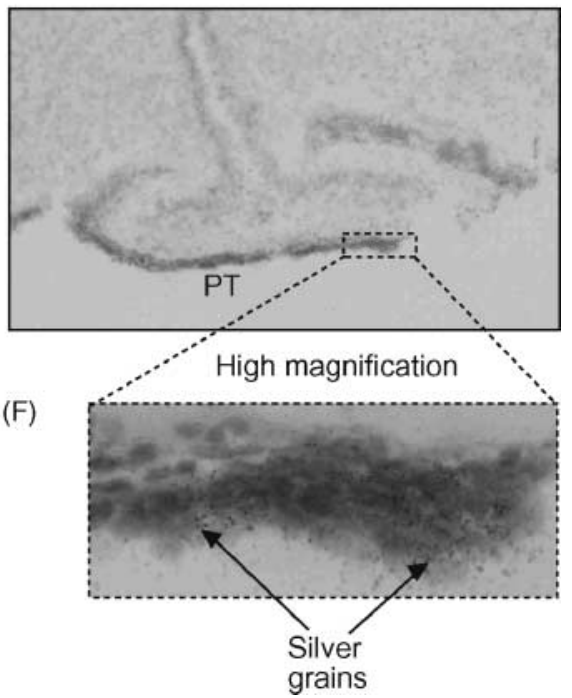

Figure 1 (A) NMU mRNA expression in the rat brain. Specific signal is clearly localised to the pars tuberalis at the ventral edge of the median eminence. (B) Ob-Rb mRNA expression in the mediobasal hypothalamus, the area of the median eminence and pars tuberalis is devoid of signal. (C) Stained section that gave rise to image in (B), showing the location of the pars tuberalis. (D) Dark-field image of NMU gene expression in the rat pars tuberalis. Silver grains appear white. (E) Corresponding bright-field image of the section underlying the dark-field image. (F) High magnification of brightfield image of NMU gene expression. Silver grains can clearly be seen overlying the pars tuberalis tissue. 
previously reported (not shown). However, the scarcity of these neurones in the sections observed in the present study made it impossible to carry out quantification of NMU gene expression by quantitative in situ hybridisation in the mediobasal hypothalmus. The NMU probe used in the present study has a portion of overlap with the known gene sequence of neuromedin S (NMS) and the possibility exists that some of the signal located in the present study corresponds to NMS gene expression. However, this is unlikely as NMS is almost exclusively localised to the SCN and its occurrence in the pars tuberalis has not been reported despite sections containing the closely neighbouring arcuate nuclei being observed (Mori et al. 2005).

\section{Long-term leptin challenge in fed and fasted rats by real-time} RT-PCR

Two-way ANOVA, to test the effect of treatments and/or interactions between treatments, revealed that there was a significant effect $(P<0 \cdot 01)$ of fasting to increase the expression of NMU in the dissected area, while the overall effect of leptin was not significant $(P=0 \cdot 058)$. There was no interaction between leptin and fasting as factors influencing NMU gene expression (Fig. 2). However, as the statistical significance for the effect of leptin was judged as borderline and the variability of the results was large as witnessed by the size of the standard errors, it was decided that the use of a more sensitive and region-specific technique, such as quantitative in situ hybridisation may be able to detect pars

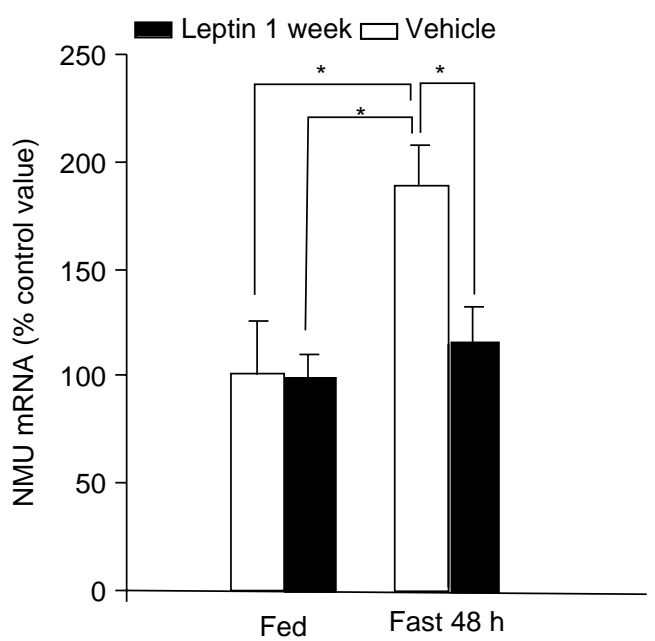

Figure 2 (A) Using real-time RT-PCR, fasting for $48 \mathrm{~h}$ was found to significantly increase NMU gene expression $(P<0 \cdot 01)$, while leptin infusion $(15 \mu \mathrm{g} /$ day) for 1 week had no overall effect on NMU expression in the pars tuberalis $(P=0 \cdot 058)$ by two-way ANOVA. Student-Newman-Keuls analysis revealed significant differences between fed vs fasted vehicle-challenged animals, and fed, leptinchallenged vs fasted, vehicle challenged, and fasted vehiclechallenged vs fasted leptin-challenged groups. Differences between individual groups are indicated by $* P<0 \cdot 05$. tuberalis-specific changes in response to leptin treatment. Student-Newman-Keuls analysis revealed a significant difference $(P<0 \cdot 05)$ between fed groups versus fasted vehicle-treated group, and fasted vehicle-treated and fasted leptin-treated groups.

Short-term leptin challenge in fed and fasted rats by quantitative in situ hybridisation

Two-way ANOVA revealed that there was an effect of $48 \mathrm{~h}$ fasting on the level of NMU gene expression in the pars tuberalis when compared to rats fed ad libitum $(P<0 \cdot 01)$; fasting increased NMU gene expression (Fig. 3A). There was also an effect of i.c.v. leptin treatment on the level of NMU expression in the pars tuberalis; leptin reduced NMU expression $(P<0 \cdot 05)$. There was no interaction between fasting and leptin as factors influencing NMU gene expression. Student-Newman-Keuls analysis revealed a single significant difference $(P<0 \cdot 05)$ between the fed leptintreated group and the fasted control group. NMU-R2 mRNA expression was not influenced by either fasting or i.c.v. leptin injection (Fig. 3B).

Short-term ghrelin challenge in fed and fasted rats by quantitative in situ hybridisation

Two-way ANOVA revealed that there was an effect of fasting to increase NMU gene expression in the pars tuberalis $(P<0 \cdot 001)$. Ghrelin, given i.c.v., had no significant effect on NMU mRNA expression in the pars tuberalis either 1 (not shown) or $2 \mathrm{~h}$ after injection in rats fed ad libitum or $48 \mathrm{~h}$ fasted (Fig. 4A). Student-Newman-Keuls analysis revealed a significant difference $(P<0 \cdot 05)$ between the fed and the fasted groups. No significant effect of fasting or ghrelin treatment (1 or $2 \mathrm{~h}$ ) was observed on NMU-R2 gene expression in the PVN (Fig. 4B).

Long-term leptin challenge in fed and fasted rats by quantitative in situ hybridisation

Long-term i.c.v. leptin infusion $(15 \mu \mathrm{g} /$ day) significantly decreased food intake and body weight, as described earlier (Nogueiras et al. 2004). The final body weight of leptintreated rats was $310 \pm 7 \mathrm{~g}$ compared to $350 \pm 5 \mathrm{~g}(P<0 \cdot 001)$ for the saline infused animals. Daily food intake for the leptininfused animals was $19 \pm 0.9 \mathrm{~g}$ compared to $27 \pm 0.5 \mathrm{~g}$ for the saline-infused animals $(P<0 \cdot 001)$. Two-way ANOVA revealed that the leptin-treated group had significantly lower NMU mRNA levels in the pars tuberalis compared to vehicle-treated animals $(P<0 \cdot 001)$, and that fasting increased NMU gene expression $(P<0 \cdot 05)$. Student-Newman-Keuls analysis revealed significant differences $(P<0 \cdot 05)$ between all groups (Fig. 5A). However, long-term leptin administration had no significant effect on NMU-R2 mRNA levels in either fed or fasted rats (Fig. 5B). 

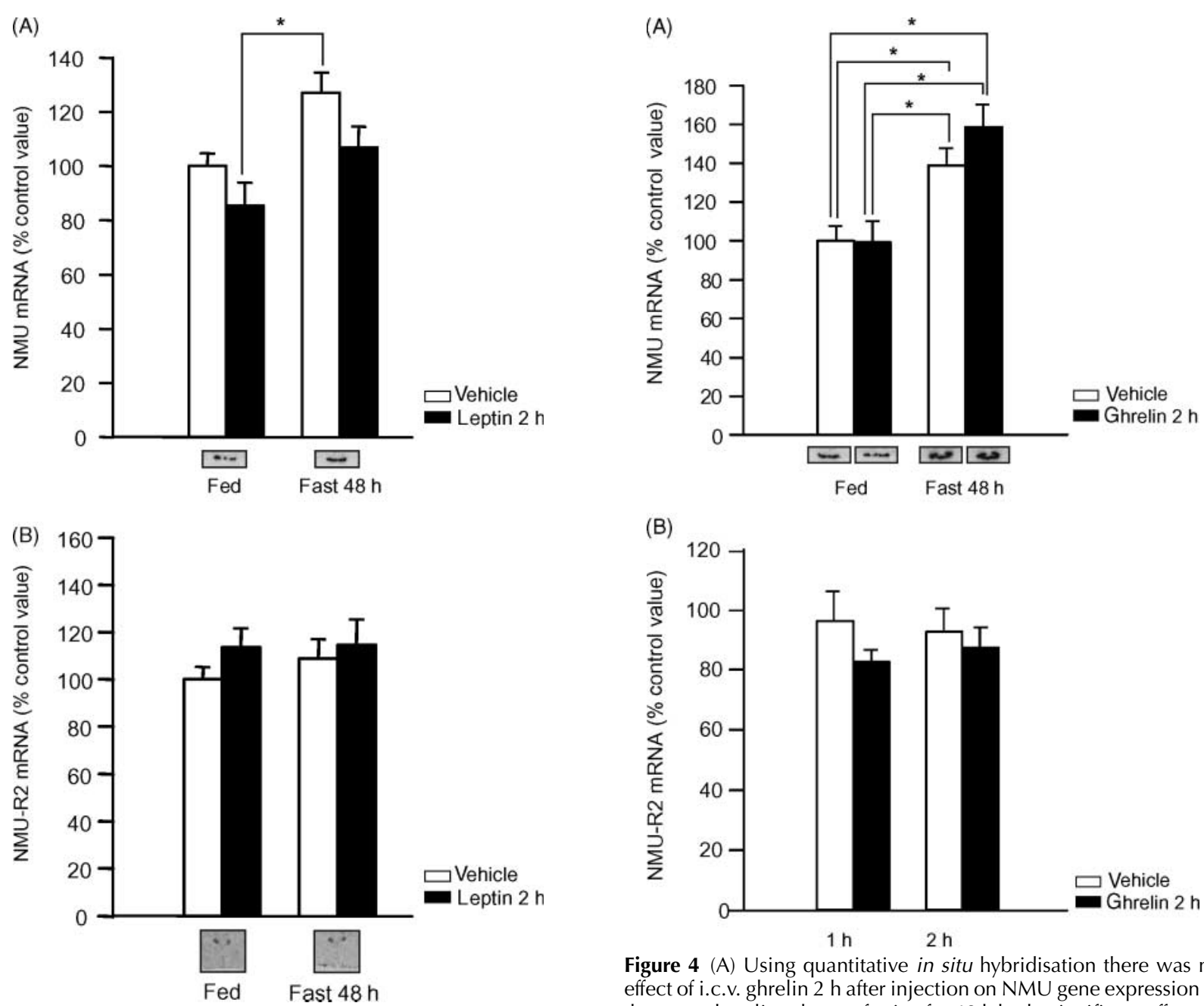

Figure 3 (A) Using quantitative in situ hybridisation both fasting for $48 \mathrm{~h}$ and i.c.v. leptin $2 \mathrm{~h}$ after injection had significant effects on NMU gene expression $(P<0 \cdot 01,<0.05)$ in the pars tuberalis by two-way ANOVA. Student-Newman-Keuls analysis revealed that there was a significant difference between rats fed ad libitum, leptin-injected and $48 \mathrm{~h}$ fasted, $* P<0 \cdot 05$. (B) NMU-R2 gene expression in the PVN, where no significant difference was detected. Representative autoradiographic images underlie the histograms.

\section{Leptin time and dose response}

Leptin i.c.v. infusion of either 1 or $5 \mu \mathrm{g} /$ day for 1 week, significantly $(P<0 \cdot 01$ and $<0 \cdot 001$ respectively) decreased the level of NMU expression. The level of NMU expression was significantly lower $(P<0 \cdot 01)$ after infusion of $5 \mu \mathrm{g} /$ day leptin than after $1 \mu \mathrm{g} /$ day leptin (Fig. 6A). Leptin i.c.v. infusion of $15 \mu \mathrm{g} /$ day, both for $24(P<0 \cdot 01)$ or $48 \mathrm{~h}$ $(P<0 \cdot 001)$, significantly decreased NMU gene expression in the rat pars tuberalis compared to control animals. The level of NMU gene expression at $48 \mathrm{~h}$ was significantly lower than that at $24 \mathrm{~h}(P<0 \cdot 05$; Fig. 6B).

Figure 4 (A) Using quantitative in situ hybridisation there was no effect of i.c.v. ghrelin $2 \mathrm{~h}$ after injection on NMU gene expression in the pars tuberalis, whereas fasting for $48 \mathrm{~h}$ had a significant effect on NMU gene expression $(P<0 \cdot 001)$ by two-way ANOVA. StudentNewman-Keuls analysis revealed that there was a significant difference between all fed and fasted groups irrespective of ghrelin treatment. Representative autoradiographic images underlie the histograms. (B) NMU-R2 gene expression in the PVN, where no significant difference was detected.

\section{Discussion}

The present study shows that NMU gene expression on the rat pars tuberalis is increased in response to fasting and decreased in a dose- and time-dependent manner by central leptin administration. Central ghrelin administration at the times and doses tested had no significant effect on NMU gene expression. These results indicate that NMU gene expression in the pars tuberalis is responsive to nutritional status and leptin. These results also emphasise the importance of using a highly sensitive and regionspecific technique in the analysis of homogeneous tissues such as the hypothalamus and the adjoining pars tuberalis. The function of NMU in the pars tuberalis is at present unclear. The pars tuberalis is thought to function as a timer of seasonal physiology, 

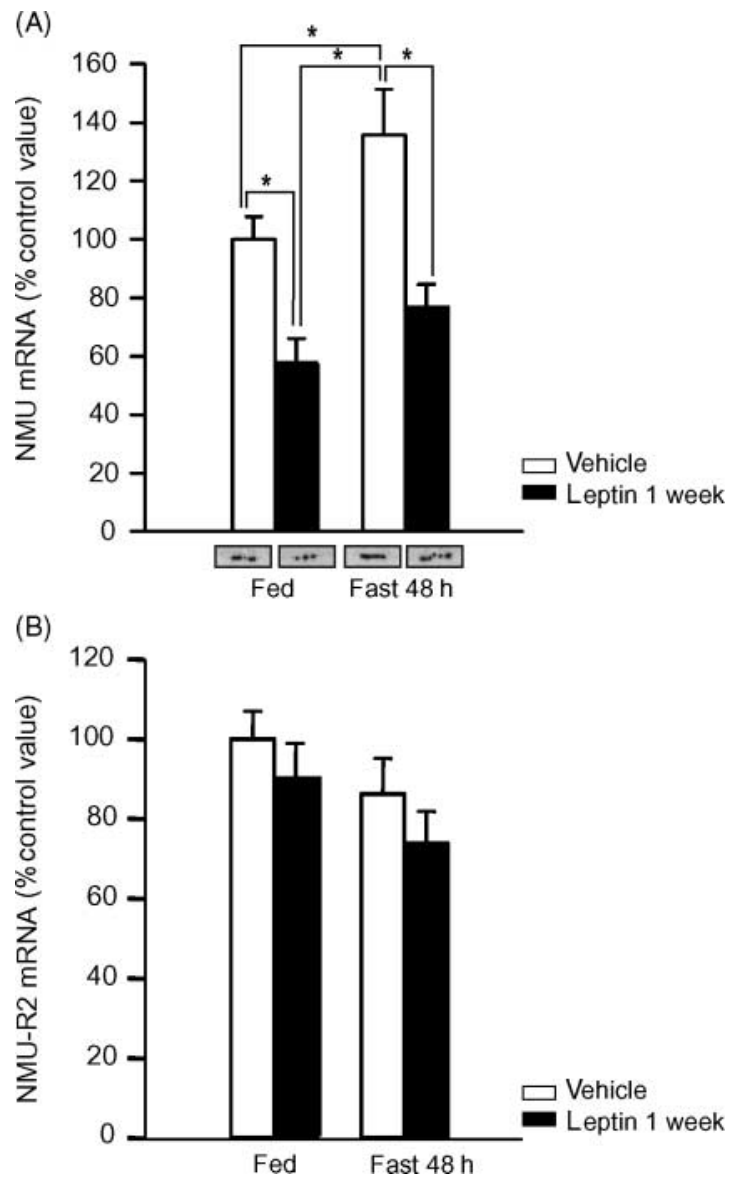

Figure 5 (A) Using quantitative in situ hybridisation, leptin infusion (15 $\mu \mathrm{g} /$ day) for 1 week was found to decrease NMU expression in the pars tuberalis $(P<0 \cdot 01)$, while fasting for $48 \mathrm{~h}$ significantly increased gene expression $(P<0 \cdot 01)$ by two-way ANOVA. StudentNewman-Keuls analysis revealed significant differences between fed vs fasted vehicle-challenged animals, and fed, vehicle-

challenged vs fed leptin-challenged, and fasted vehicle-challenged vs fasted leptin-challenged. Differences between individual groups are indicated by $* P<0 \cdot 05$. Representative autoradiographic images underlie the histograms. (B) NMU-R2 gene expression in the PVN, where no significant difference was detected.

integrating the melatonin signal with endogenous cycles of clock genes expressed in this region of the pituitary. As such, the pars tuberalis is influential in controlling the annual cycles of reproduction, pelage growth and moulting and appetite and body weight in seasonal animals (Lincoln et al. 2003). The laboratory rat maintains highly dampened seasonal cycles in reproduction and energy balance, which appear to be straindependent, but may be unmasked by food restriction (Francisco et al. 2004).

The role of central NMU in food intake and energy balance is complex. In the rat, while a single i.c.v. injection of NMU gives a clear catabolic response, increasing core body temperature and locomotor activity, reducing food intake (Nakazato et al. 2000) and acute administration of NMU into the PVN has clear anorexigenic effects (Wren et al. 2002);
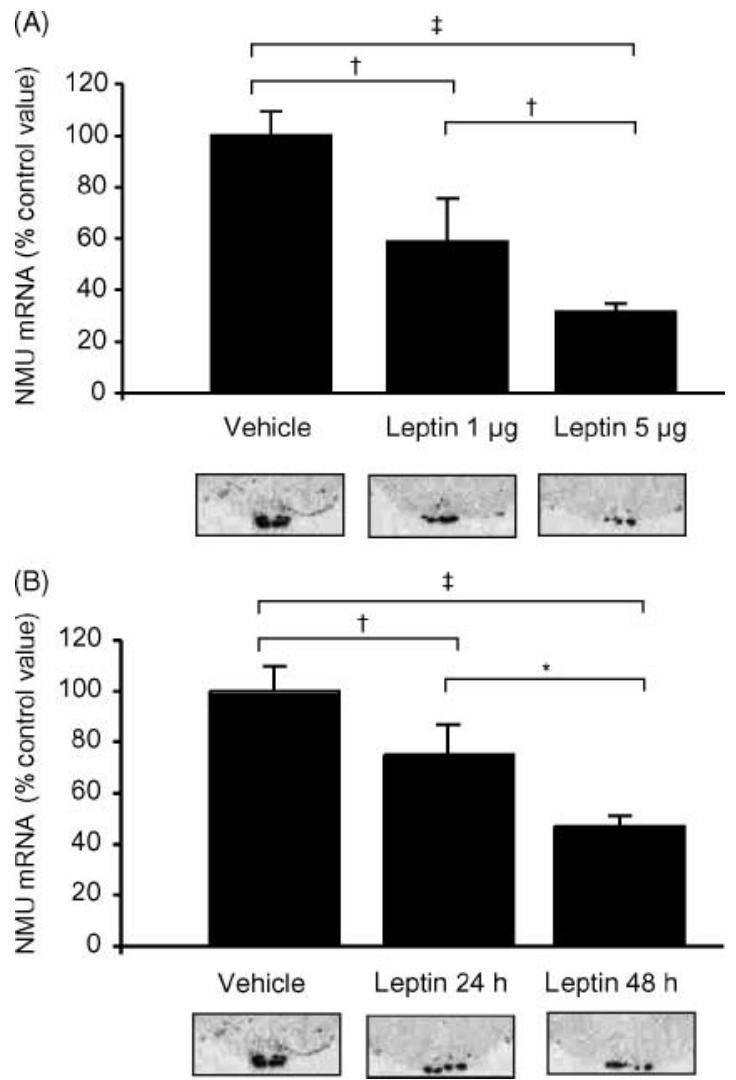

Figure 6 (A) Effect of leptin on NMU mRNA expression in the pars tuberalis after 1 week of infusion measured by quantitative in situ hybridisation, $+P<0 \cdot 01$ leptin $1 \mu \mathrm{g}$ /day vs vehicle, $¥ P<0 \cdot 001$ leptin $5 \mu \mathrm{g}$ /day vs vehicle, $+P<0.011 \mu \mathrm{g}$ /day vs $5 \mu \mathrm{g} /$ day by oneway ANOVA. (B) Effect of leptin (15 $\mu \mathrm{g} /$ day) on NMU mRNA expression in the pars tuberalis; $+P<0 \cdot 0124 \mathrm{~h}$ leptin vs vehicle and $¥ P<0 \cdot 00148 \mathrm{~h}$ leptin vs vehicle and $* P<0 \cdot 0524 \mathrm{~h}$ leptin vs $48 \mathrm{~h}$ leptin by one-way ANOVA. Representative autoradiographic images of NMU gene expression in the pars tuberalis from treatments underlie the histograms.

however, chronic injections of NMU into the PVN have no effect on food intake or body weight. Nevertheless, the NMU knockout mouse shows clear hyperphagia and obesity (Hanada et al. 2004) and the transgenic mouse overexpressing NMU is lean and hypophagic (Kowalski et al. 2005). Recently, it has been demonstrated that at least some of the effects of leptin are mediated via NMU (Jethwa et al. 2005). It has been shown that fasting increases NMU mRNA levels in the DMH hypothalamic nuclei of mice (Graham et al. 2003). In addition, leptin-deficient $o b / o b$ mice have been reported to have higher NMU mRNA expression in the DMH than lean littermates. In both cases, leptin levels are low or absent and the animals have a strong drive to eat, contrasting with the reported anorexigenic effects of NMU. However, NMU gene expression in the SCN has been reported to be higher in the $o b / o b$ mouse compared to lean littermates (Howard et al. 2000) and show clear circadian changes in the level of expression (Graham et al. 2005), 
linking energy balance and circadian clock function. In the Zucker fatty rat, lower levels of gene expression of NMU in the pars tuberalis and pars distalis of the pituitary, and in the NTS, have been reported compared to the lean animal (Ivanov et al. 2002), and fasting has been found to decrease NMU expression in the nuclei of the solitary tract and significantly decrease NMU gene expression in the pars distalis of the pituitary (Ivanov et al. 2002) and VMH (Howard et al. 2000). This reduced NMU gene expression appears to be linked to an absent or diminished leptin signal. In contrast, the results of the present study show clearly that fasting for $48 \mathrm{~h}$ upregulates NMU gene expression in the pars tuberalis. This finding, like those in the mouse detailed above, is difficult to explain in the context of NMU acting in the brain as an anorexigenic agent and may indicate that the function of NMU in the pars tuberalis is unrelated to appetite and energy balance control.

Negative energy balance induced by fasting does, however, clearly upregulate NMU gene expression on the rat pars tuberalis. The present study also clearly shows the influence of leptin on NMU expression in the rat pars tuberalis with discernable decreases in the expression of NMU in both fed and fasted rats $2 \mathrm{~h}$ after a single i.c.v. injection of leptin and more marked decreases after infusion of leptin for 1 week. Downregulation of gene expression can be difficult to demonstrate as the half-life of the RNA transcripts differ and downregulation of certain genes may take longer to become apparent. This may explain a contradictory report of the effect of leptin on NMU gene expression in the pars tuberalis (identified as the arcuate nuclei in that study), in which length of time after leptin administration was not documented (Hanada et al. 2004). In the present study, while a single i.c.v. leptin injection was shown to have an effect on NMU expression, using quantitative in situ hybridisation, the effect became more pronounced in rats challenged for $24 \mathrm{~h}$ or longer. While leptin treatment clearly downregulated NMU gene expression in both a time- and dose-dependent manner, the lack of leptin receptor $(\mathrm{Ob}-\mathrm{Rb})$ expression on the rat pars tuberalis indicates that the affect of leptin on NMU gene expression is indirect. A direct influence of leptin on NMU expression is unlikely as leptin receptors are absent from the rat pars tuberalis. However, the pars tuberalis is in close contact with the median eminence, both directly as the two tissues oppose each other and indirectly via the blood supply in the primary portal plexus (Wittkowski et al. 1992), meaning that any secretion from the median eminence reaches the pars tuberalis almost immediately and in relatively high concentrations. Thus, any influence of leptin on the hypothalamus could impact the output of the median eminence, which in turn could influence NMU gene expression in the pars tuberalis. When leptin levels are low, ghrelin levels tend to be high (Cummings \& Foster 2003, Kim et al. 2003), making ghrelin another likely candidate for mediating this effect of negative energy balance on NMU expression. However, the present study found no demonstrable effects of i.c.v. ghrelin administration on the level of NMU expression at the doses and times tested.

The downregulation of NMU gene expression in the pars tuberalis by leptin is also at odds with the known anorexigenic action of NMU and further suggests that the function of NMU in the pars tuberalis is unrelated to appetite control and energy homeostasis. As already detailed, the pars tuberalis is a region of the pituitary that is involved in seasonality and is a major site of action of melatonin (Williams 1989). The pars tuberalis also controls prolactin release from the pars distalis via an, as yet, unidentified, juxtacrine agent (Morgan et al. 1996, Johnston 2004). Interestingly, a novel 33-residue peptide derived from the NMU proprotein has recently been identified and shows potent prolactin-releasing activity when administered i.c.v. (Williams et al. 2001, Mori et al. 2005). In the present study, the interaction of nutritional status and leptin with NMU gene expression in the pars tuberalis is clearly evidenced. However, the function of NMU in the pars tuberalis is not known and the relevance of the relationship between nutritional status, leptin and the level of NMU gene expression in this region of the pituitary is not clear at present.

\section{Acknowledgements}

We would like to thank Dr G Horgan, Biostatistics Scotland (BIOSS) at the Rowett Research Institute for expert statistical advice.

\section{Funding}

This work was supported by the Ministerio de Ciencia y Tecnologia in Spain and the Scottish Executive Environment \& Rural Affairs Department in the UK. Rubén Nogueiras was a recipient of a Research Training Grant at Obes ${ }^{\mathrm{e}}$ hool funded by EC Framework V Program: HPMT-CT-2001-00410. Sharon Mitchell was funded by EC Framework V: QLK6-2002-02288. The authors declare that there is no conflict of interest that would prejudice the impartiality of this scientific work.

\section{References}

Ahren B, Mansson S, Gingerich RL \& Havel PJ 1997 Regulation of plasma leptin in mice: influence of age, high-fat diet, and fasting. American Journal of Physiology 273 R113-R120.

Cowley MA, Smith RG, Diano S, Tschop M, Pronchuk N, Grove KL, Strasburger CJ, Bidlingmaier M, Esterman M, Heiman ML et al. 2003 The distribution and mechanism of action of ghrelin in the CNS demonstrates a novel hypothalamic circuit regulating energy homeostasis. Neuron 37 649-661.

Cummings DE \& Foster KE 2003 Ghrelin-leptin tango in body-weight regulation. Gastroenterology 124 1532-1535.

Elias CF, Aschkenasi C, Lee C, Kelly J, Ahima RS, Bjorbaek C, Flier JS, Saper CB \& Elmquist JK 1999 Leptin differentially regulates NPY and POMC neurons projecting to the lateral hypothalamic area. Neuron $\mathbf{2 3}$ 775-786. 
Francisco NR, Raymond CM \& Heideman PD 2004 Short photoperiod inhibition of growth in body mass and reproduction in ACI, BUF, and PVG inbred rats. Reproduction 128 857-862.

Graham ES, Turnbull Y, Fotheringham P, Nilaweera K, Mercer JG, Morgan PJ \& Barrett P 2003 Neuromedin U and neuromedin U receptor-2 expression in the mouse and rat hypothalamus: effects of nutritional status. Journal of Neurochemistry 87 1165-1173.

Graham ES, Littlewood P, Turnbull Y, Mercer JG, Morgan PJ \& Barrett P 2005 Neuromedin- $\mathrm{U}$ is regulated by the circadian clock in the SCN of the mouse. European Journal of Neuroscience 21 814-819.

Guan XM, Yu H, Jiang Q, Van der Ploeg LHT \& Liu Q 2001 Distribution of neuromedin $\mathrm{U}$ receptor subtype $2 \mathrm{mRNA}$ in the rat brain. Gene Expression Patterns 1 1-4.

Hanada R, Nakazato M, Murakami N, Sakihara S, Yoshimatsu H, Toshinai K, Hanada T, Suda T, Kangawa K, Matsukura S \& Sakata T 2001 A role for neuromedin $\mathrm{U}$ in stress response. Biochemical and Biophysical Research Communications 289 225-228.

Hanada R, Teranishi H, Pearson JT, Kurokawa M, Hosoda H, Fukushima N, Fukue Y, Serino R, Fujihara H, Ueta Y et al. 2004 Neuromedin U has a novel anorexigenic effect independent of the leptin signaling pathway. Nature Medicine 10 1067-1073.

Howard AD, Wang RP, Pong SS, Mellin TN, Strack A, Guan XM, Zeng ZZ, Williams DL, Feighner SD, Nunes CN et al. 2000 Identification of receptors for neuromedin $U$ and its role in feeding. Nature 406 70-74.

Ivanov TR, Lawrence CB, Stanley PJ \& Luckman SM 2002 Evaluation of neuromedin $\mathrm{U}$ actions in energy homeostasis and pituitary function. Endocrinology 143 3813-3821.

Jethwa PH, Small CJ, Smith KL, Seth A, Darch SJ, Abbott CR, Murphy KG, Todd JF, Ghatei MA \& Bloom SR 2005 Neuromedin U has a physiological role in the regulation of food intake and partially mediates the effects of leptin. American Journal of Physiology - Endocrinology and Metabolism 289 E301-E305.

Johnston JD 2004 Photoperiodic regulation of prolactin secretion: changes in intra-pituitary signalling and lactotroph heterogeneity. Journal of Endocrinology 180 351-356.

Kamegai J, Tamura H, Shimizu T, Ishii S, Sugihara H \& Wakabayashi I 2001 Chronic central infusion of ghrelin increases hypothalamic neuropeptide $\mathrm{Y}$ and agouti-related protein mRNA levels and body weight in rats. Diabetes $502438-2443$

Keim NL, Stern JS \& Havel PJ 1998 Relation between circulating leptin concentrations and appetite during a prolonged, moderate energy deficit in women. American Journal of Clinical Nutrition 68 794-801.

Kim MS, Yoon CY, Park KH, Shin CS, Park KS, Kim SY, Cho BY \& Lee HK 2003 Changes in ghrelin and ghrelin receptor expression according to feeding status. Neuroreport 14 1317-1320.

Kowalski TJ, Spar BD, Markowitz L, Maguire M, Golovko A, Yang S, Farley C, Cook JA, Tetzloff G, Hoos L et al. 2005 Transgenic overexpression of neuromedin $\mathrm{U}$ promotes leanness and hypophagia in mice. Journal of Endocrinology 185 151-164.

Lee HM, Wang GY, Englander EW, Kojima M \& Greeley GH 2002 Ghrelin, a new gastrointestinal endocrine peptide that stimulates insulin secretion: enteric distribution, ontogeny, influence of endocrine, and dietary manipulations. Endocrinology 143 185-190.

Lincoln GA, Andersson H \& Loudon A 2003 Clock genes in calendar cells as the basis of annual timekeeping in mammals - a unifying hypothesis. Journal of Endocrinology 179 1-13.

Lopez M, Seoane L, Carmen Garcia M, Lago F, Casanueva FF, Senaris R \& Dieguez C 2000 Leptin regulation of prepro-orexin and orexin receptor mRNA levels in the hypothalamus. Biochemical and Biophysical Research Communications 269 41-45.
Minamino N, Kangawa K \& Matsuo H 1985 Neuromedin-U-8 and neuromedin-U-25 - novel uterus stimulating and hypertensive peptides identified in porcine spinal-cord. Biochemical and Biophysical Research Communications 130 1078-1085.

Mitchell SE, Robinson JJ, King ME, McKelvey WAC \& Williams LM 2002 Interleukin 8 in the cervix of non-pregnant ewes. Reproduction $\mathbf{1 2 4}$ 409-416.

Morgan PJ, Webster CA, Mercer JG, Ross AW, Hazlerigg DG, MacLean A \& Barrett P 1996 The ovine pars tuberalis secretes a factor(s) that regulates gene expression in both lactotropic and nonlactotropic pituitary cells. Endocrinology 137 4018-4026.

Mori K, Miyazato M, Ida T, Murakami N, Serino R, Ueta Y, Kojima M \& Kangawa K 2005 Identification of neuromedin S and its possible role in the mammalian circadian oscillator system. EMBO Journal 24 325-335.

Nakahara K, Hanada R, Murakami N, Teranishi H, Ohgusu H, Fukushima N, Moriyama M, Ida T, Kangawa K \& Kojima M 2004 The gut-brain peptide neuromedin $\mathrm{U}$ is involved in the mammalian circadian oscillator system. Biochemical and Biophysical Research Communications 318 156-161.

Nakazato M, Hanada R, Murakami N, Date Y, Mondal MS, Kojima M, Yoshimatsu H, Kangawa K \& Matsukura S 2000 Central effects of neuromedin $\mathrm{U}$ in the regulation of energy homeostasis. Biochemical and Biophysical Research Communications 277 191-194.

Nogueiras R, Tovar S, Mitchell SE, Rayner DV, Archer ZA, Dieguez C \& Williams LM 2004 Regulation of growth hormone secretagogue receptor gene expression in the arcuate nuclei of the rat by leptin and ghrelin. Diabetes 53 2552-2558.

Quan H, Funabashi T, Furuta M \& Kimura F 2003 Effects of neuromedin U on the pulsatile $\mathrm{LH}$ secretion in ovariectomized rats in association with feeding conditions. Biochemical and Biophysical Research Communications 311 $721-727$.

Seoane LM, Lopez M, Tovar S, Casanueva FF, Senaris R \& Dieguez C 2003 Agouti-related peptide, neuropeptide $\mathrm{Y}$, and somatostatin- producing neurons are targets for ghrelin actions in the rat hypothalamus. Endocrinology 144 544-551.

Takahashi JS \& Zatz M 1982 Regulation of circadian rhythmicity. Science 217 1104-1111.

Thompson EL, Murphy KG, Todd JF, Martin NM, Small CJ, Ghatei MA \& Bloom SR 2004 Chronic administration of NMU into the paraventricular nucleus stimulates the HPA axis but does not influence food intake or body weight. Biochemical and Biophysical Research Communications 323 65-71.

Tschop M, Weyer C, Tataranni PA, Devanarayan V, Ravussin E \& Heiman ML 2001 Circulating Ghrelin levels are decreased in human obesity. Diabetes $\mathbf{5 0}$ 707-709.

Williams LM 1989 Melatonin-binding sites in the rat brain and pituitary mapped by in-vitro autoradiography. Journal of Molecular Endocrinology 3 71-75

Williams G, Bing C, Cai XJ, Harrold JA, King PJ \& Liu XH 2001 The hypothalamus and the control of energy homeostasis different circuits, different purposes. Physiology and Behavior 74 683-701.

Wittkowski W, Schulze-Bonhage A \& Bockers TM 1992 The pars tuberalis of the hypophysis: a modulator of the pars distalis. Acta Endocrinologica (Copenh) $126285-290$.

Wren AM, Small CJ, Abbott CR, Jethwa PH, Kennedy AR, Murphy KG, Stanley SA, Zollner AN, Ghatei MA \& Bloom SR 2002 Hypothalamic actions of neuromedin U. Endocrinology 143 4227-4234.

Zigman JM \& Elmquist JK 2003 Minireview: from anorexia to obesity - the yin and yang of body weight control. Endocrinology 144 3749-3756. Received in final form 3 April 2006
Accepted 9 May 2006 